\title{
Is smoking a communicable disease? Effect of exposure to ever smokers in school tutor groups on the risk of incident smoking in the first year of secondary school
}

\author{
A Molyneux, S Lewis, M Antoniak, R Hubbard, A McNeill, C Godfrey, R Madeley, \\ J Britton
}

Tobacco Control 2002;11:241-245

See end of article for authors' affiliations

Correspondence to:

Correspondence to:
Professor John Britton, University of Nottingham,

Division of Respiratory

Medicine, City Hospital

Nottingham NG5 IPB, UK;

j.britton@virgin.net

Received 19 September 2001 and revision requested

20 December 2001

Accepted 27 April 2002

\begin{abstract}
Objective: To estimate the effect of joining a first year secondary school tutor group with a high prevalence of ever smoking on the risk of incident smoking in schoolchildren.

Design: Cross-sectional questionnaire survey.

Setting: 10 randomly selected secondary schools in Nottinghamshire, UK.

Participants: Pupils in years (grades) $7-11$ (aged $11-16$ years).

Main outcome measure: Incident smoking in the first year of secondary education, defined as pupils who reported smoking their first cigarette during year 7 .

Results: Of 6522 pupils (75\% of those eligible) who completed the questionnaire, $17 \%$ were current smokers and $49 \%$ had ever smoked, of whom $23 \%$ had started smoking in year 7 . Incident smoking in year 7 was more common in girls, in children with parents or siblings who smoke, and in more deprived children, and was independently increased in relation to the proportion of ever smokers in the year 7 tutor group joined by the child ladjusted odds ratio of incident smoking for a child joining a year 7 tutor group in the highest relative to the lowest quartile of ever smoking prevalence $1.45,95 \%$ confidence interval (CI) 1.11 to 1.89). Exposure to ever smokers in year 7 tutor groups also accounted for most of the increased risk of incident smoking associated with socioeconomic deprivation.

Conclusions: The risk of incident smoking in children entering secondary education is independently increased by exposure to other ever smokers in school tutor groups. Incident smoking in adolescents is thus to some extent a communicable disorder, and may be partly preventable by policies that reduce exposure to smoking at school.
\end{abstract}

igarette smoking is the most important avoidable cause of morbidity and premature death in the developed world. In the UK there are 13 million smokers, ${ }^{1}$ half of whom will die prematurely as a result of smoking. ${ }^{2}$ Since the majority of smokers are socioeconomically disadvantaged, ${ }^{3}$ preventing smoking would improve public health and reduce social inequality in health more than any other intervention. It is therefore important to determine why people begin smoking; because most smokers in the UK start smoking soon after starting secondary education, ${ }^{34}$ it is especially important to identify the risk factors for incident smoking during this period.

It is well recognised that children who smoke tend to have friends who smoke, but it has never been clear whether this association arises from a causal influence on smoking behaviour, or from peer group selection by smoking children. ${ }^{5-8}$ Adolescent smokers also tend to overestimate smoking among their peers, ${ }^{9}{ }^{10}$ causing bias in the measurement of peer group smoking. However, when children in the UK move from primary to secondary education they join new secondary school tutor groups of 20-30 pupils (students) that are selected by the school to promote the mixing of children from different areas, academic ability, and friendship groups. Since children stay in these tutor groups for most lessons during the first year of secondary school, they are exposed to new peer groups with different levels of smoking that are additional to and independent from exposure to smoking in pre-existing friendship groups. We hypothesised that if peer group smoking has an independent effect on the individual pupil's risk of starting smoking then the number of ever smokers in these new tutor groups should have an effect on the uptake of smoking during the first year of secondary education (year 7).
We have tested this hypothesis using data from a crosssectional survey of smoking behaviour of pupils in 10 secondary schools in Nottinghamshire, UK.

\section{METHODS}

We surveyed pupils in years (grades) 7-11 (aged 11-16 years) in 10 secondary schools selected at random from a local education authority list of all 50 state secondary schools in Nottinghamshire, after first excluding four schools due to be inspected during the study period, and two that did not provide information on the number of pupils attending the school. Head teachers of these schools were approached and asked for permission to carry out the survey, which was approved by the Nottingham City Hospital ethics committee.

From January to March 2001 each pupil in years 7-11 was asked to complete a questionnaire adapted from the Office for National Statistics Social Survey Division 1998 Teenage Smoking Attitudes Questionnaire. ${ }^{8}$ The questionnaire was designed for confidential self completion, under examination conditions with teacher supervision, during a single personal, social and health education period (typically lasting 30 to 40 minutes), and elicited the name, school tutor group, and home post code of each pupil. Questions on current and past smoking ascertained whether the pupils had never smoked, had tried smoking once, used to smoke but did not now, sometimes smoke but no more than one cigarette per week (occasional smokers), or smoked at least one cigarette per week (regular smokers). ${ }^{11}$ Ever smokers were asked the school year and age at which they started smoking; all respondents were asked whether anyone in their family smokes at the moment with a choice of father, mother and brother/sister for 
Table 1 Numbers of children in sample and percentage prevalence of smoking, by sex and year

\begin{tabular}{|c|c|c|c|c|c|c|c|c|c|c|c|c|c|c|c|c|c|c|}
\hline \multirow{2}{*}{$\begin{array}{l}\text { Smoking } \\
\text { behaviour }\end{array}$} & \multicolumn{3}{|c|}{ Year 7} & \multicolumn{3}{|c|}{ Year 8} & \multicolumn{3}{|c|}{ Year 9} & \multicolumn{3}{|c|}{ Year 10} & \multicolumn{3}{|c|}{ Year 11} & \multirow{2}{*}{$\begin{array}{l}\text { All } \\
\text { boys }\end{array}$} & \multirow{2}{*}{$\begin{array}{l}\text { All } \\
\text { girls }\end{array}$} & \multirow[b]{2}{*}{ Total } \\
\hline & Boys & Girls & Total & Boys & Girls & Total & Boys & Girls & Total & Boys & Girls & Total & Boys & Girls & Total & & & \\
\hline Number & 606 & 580 & 1186 & 726 & 616 & 1342 & 657 & 642 & 1299 & 771 & 717 & 1488 & 606 & 601 & 1207 & 3366 & 3156 & 6522 \\
\hline Never smoked & 75.6 & 75.5 & 75.6 & 68.6 & 62.5 & 65.8 & 52.5 & 44.6 & 48.6 & 40.6 & 30.0 & 35.5 & 42.4 & 24.5 & 33.5 & 55.6 & 46.6 & 51.2 \\
\hline Smoked once & 17.0 & 15.9 & 16.4 & 18.3 & 22.9 & 20.4 & 25.3 & 20.4 & 22.9 & 27.2 & 20.2 & 23.9 & 21.6 & 20.5 & 21.0 & 22.1 & 20.0 & 21.1 \\
\hline Used to smoke & 4.3 & 6.6 & 5.4 & 7.7 & 10.1 & 8.8 & 7.9 & 13.4 & 10.6 & 11.4 & 18.7 & 14.9 & 12.5 & 18.1 & 15.3 & 8.9 & 13.6 & 11.6 \\
\hline Current smoker & 3.1 & 2.1 & 2.7 & 5.4 & 4.6 & 5.0 & 14.3 & 21.7 & 18.0 & 20.8 & 31.1 & 25.7 & 23.5 & 36.9 & 30.2 & 13.5 & 19.8 & 16.5 \\
\hline Regular & 1.5 & 1.2 & 1.4 & 2.9 & 2.4 & 2.7 & 10.4 & 14.0 & 12.2 & 14.7 & 25.0 & 19.6 & 18.5 & 28.1 & 23.3 & 9.6 & 14.6 & 12.0 \\
\hline Occasional & 1.7 & 0.9 & 1.3 & 2.5 & 2.1 & 2.3 & 4.0 & 7.6 & 5.8 & 6.1 & 6.1 & 6.1 & 5.0 & 8.8 & 6.9 & 3.9 & 5.2 & 4.5 \\
\hline
\end{tabular}

those answering positively. Supervising teachers were asked to confirm that each pupil's name and tutor group had been correctly completed, and that any absentees were asked to complete a questionnaire on a subsequent occasion.

This was a second cross-sectional survey carried out as part of a larger project to study adolescent smoking behaviour and develop smoking cessation interventions for adolescents. Data from this survey have been used as they contained more complete information than the previous survey on the school year in which most smokers smoked their first cigarette.

Regular and occasional smokers were categorised as current smokers. Parental smoking was categorised as neither parent smokes, one parent smokes, or both parents smoke, and sibling smoking was categorised as non-smoking sibling(s), smoking sibling(s), or no siblings (respondents answering no to the question "Do you have any brothers or sisters?"). Social deprivation was estimated for each respondent from the Townsend Material Deprivation Index, an area measure based upon 1991 census data (the most recent available) on unemployment, overcrowding, car and house ownership, expressed as a standardised residual relative to the mean for England and Wales (negative values reflecting lesser and positive values greater degrees of deprivation), and available for each census enumeration district in England and Wales from Manchester Information and Associated Services (MIMAS), Manchester Computing, University of Manchester. ${ }^{12}$ Each respondent's home postcode was converted to a census enumeration district code using the PC2ED facility (based on the 1998 Central Postcode Directory, MIMAS, http://census.ac.uk/cdu/ Datasets / Lookup_tables / Postal / Postcode _ Enumeration District_Director y.h.htm\#3); this code was use to obtain the Townsend Index from the MIMAS database.

\section{Statistical analysis}

We used simple cross tabulation to calculate the prevalence of smoking in all respondents, and by school, sex, and school year. We used the school year in which pupils who had ever smoked reported that they had tried their first cigarette to estimate retrospectively the proportion of ever smokers in each tutor group at the beginning of year 7 , and to identify those who smoked their first cigarette during year 7 (incident smoking in year 7). Incident smoking in year 7 was then analysed in relation to the school year in which the questionnaire was completed, sex, social deprivation (using Townsend Index stratified into quartiles), parental smoking, sibling smoking, and tutor group ever smoking prevalence (stratified in quartiles) in univariate and multiple logistic regression in the STATA 7.0 statistical package ( Stata Corporation, Texas, USA). To take account of the clustered nature of the data we used robust standard errors adjusted for clustering by school, and by class in our multiple logistic regression analysis (the robust cluster(varname) command in STATA). We also looked for interactions between tutor group ever smoking and parental or sibling smoking, using likelihood ratio tests to determine the effect of the addition of these interactions upon the final multivariate regression model, hypothesising that the effect of tutor group ever smoking might be greater upon those pupils from non-smoking families. We used odds ratios from the final multivariate model to estimate population attributable risk fraction (PAF) for selected exposures, using the formula:

$$
P A F=p(R R-1) /[(p(R R-1))+1]
$$

where $\mathrm{p}$ is the proportion of the population exposed and RR is the risk ratio of that exposure. ${ }^{13}$

\section{RESULTS}

All 10 schools in the random sample took part in the study. Of a possible total of 8645 pupils in Years 7-11 on the school roll in these schools, 6522 pupils (75\%) returned completed questionnaires, the response rates between schools varying from 53-86\%; only one school had a response rate of less than $70 \%$ as a result of the loss of a box of completed questionnaires before collection. Of a possible total of 316 tutor groups surveyed, questionnaires were returned from 303 (96\%). The age range of respondents was $11-16$ years (mean 13.5 years), and $52 \%$ were boys. The median Townsend Index of the pupils was -0.82 (range -6.51 to 9.31). Educational achievement in the study schools, measured as the average proportion of children gaining five or more grade A to C General Certificate of Secondary Education results in 2000 was $41 \%$ (range $18-74 \%)$, which was below the respective averages for Nottinghamshire and England of $44 \%$ and $49 \%$.

Forty nine per cent of respondents had ever smoked a cigarette, and $17 \%$ were current smokers (12\% regular, $5 \%$ occasional). Current smoking was more prevalent in girls $(20 \%)$ than boys ( $14 \%$ ), increased with school year from $3 \%$ in year 7 to $30 \%$ in year 11 (table 1), and with quartile of deprivation from $12 \%$ in the least deprived to $20 \%$ in the most deprived children. Current smoking prevalence varied between schools from $11-33 \%$. The median prevalence of ever smoking in tutor groups at the start of year 7 was 14\% (range $0-48 \%$ ). Of children who had ever smoked, $23 \%$ first started smoking in year 7 and $32 \%$ had smoked their first cigarette before year 7 . Forty nine per cent of children reported that at least one parent smoked, and $20 \%$ at least one sibling.

In univariate analysis, the relative odds of incident smoking during year 7 were significantly increased in relation to sex, parental smoking, sibling smoking, deprivation index, and the proportion of ever smokers in the tutor group at the beginning of year 7 (table 2). All of these univariate effects were confirmed as independent significant predictors of incident smoking in multivariate analysis, though the effect of social deprivation was much reduced, largely by adjustment for the effect of exposure to other ever smokers (table 2). The multivariate model presented used robust standard errors to adjust for clustering by school; adjustment of the model for clustering by class produced similar results. For a non-smoking child joining a tutor group in the highest relative to the lowest 
Table 2 Unadjusted and adjusted risk factors for incident smoking in year 7

\begin{tabular}{|c|c|c|c|c|c|c|}
\hline Risk factor & Unadjusted OR & $95 \% \mathrm{Cl}$ & $\mathrm{p}\left(\chi^{2}\right.$ tests $)$ & Adjusted OR* & $95 \% \mathrm{Cl}$ & $\begin{array}{l}\text { p (likelihood } \\
\text { ratio tests) }\end{array}$ \\
\hline \multicolumn{7}{|l|}{ Year of questionnaire completion } \\
\hline 7 & 1 & & & 1 & & \\
\hline 8 & 2.91 & 2.04 to 4.15 & & 2.74 & 1.85 to 4.06 & \\
\hline 9 & 3.70 & 2.61 to 5.24 & & 3.57 & 2.42 to 5.27 & \\
\hline 10 & 5.13 & 3.66 to 7.19 & & 4.23 & 2.89 to 6.17 & \\
\hline 11 & 4.41 & 3.12 to 6.24 & $<0.001$ & 3.85 & 2.62 to 5.65 & $<0.001$ \\
\hline \multicolumn{7}{|c|}{2.02010 .00} \\
\hline Boy & 1 & & & 1 & & \\
\hline Girl & 1.59 & 1.36 to 1.86 & $<0.001$ & 1.57 & 1.31 to 1.88 & $<0.001$ \\
\hline \multicolumn{7}{|l|}{ Parental smoking } \\
\hline Neither parent smokes & 1 & & & 1 & & \\
\hline Only father or mother smokes & 1.54 & 1.29 to 1.86 & & 1.35 & 1.09 to 1.66 & \\
\hline Both parents smoke & 2.45 & 2.00 to 3.00 & $<0.001$ & 2.01 & 1.59 to 2.56 & $<0.001$ \\
\hline \multicolumn{7}{|l|}{ Sibling smoking } \\
\hline Non-smoking sibling(s) & 1 & & & 1 & & \\
\hline Smoking sibling(s) & 3.22 & 2.69 to 3.85 & $<0.001$ & 2.27 & 1.85 to 2.78 & $<0.001$ \\
\hline No siblings & 0.94 & 0.67 to 1.33 & & 0.88 & 0.60 to 1.29 & \\
\hline \multicolumn{7}{|c|}{$\begin{array}{l}\text { Peer smoking: quartiles of proportion of } \\
\text { classmates who had smoked at the } \\
\text { beginning of year } 7 \text { (range) }\end{array}$} \\
\hline Lowest $(0-7.4 \%)$ & 1 & & & 1 & & \\
\hline $2(7.7-13.0 \%)$ & 1.36 & 1.08 to 1.73 & & 1.20 & 0.92 to 1.58 & \\
\hline $3(13.3-19.2 \%)$ & 1.55 & 1.22 to 1.96 & & 1.42 & 1.08 to 1.87 & \\
\hline Highest (20.0-48.0\%) & 1.48 & 1.17 to 1.87 & $0.002 \dagger$ & 1.45 & 1.11 to 1.89 & 0.023 \\
\hline \multicolumn{7}{|c|}{$\begin{array}{l}\text { Social deprivation: quartiles of Townsend } \\
\text { Index (range) }\end{array}$} \\
\hline Least deprived $(-6.51$ to -3.13$)$ & 1 & & & 1 & & \\
\hline $2(-3.12$ to -0.84$)$ & 1.31 & 1.02 to 1.68 & & 1.19 & 0.92 to 1.58 & \\
\hline $3(-0.82$ to 1.55$)$ & 1.40 & 1.10 to 1.80 & & 1.11 & 0.86 to 1.45 & \\
\hline Most deprived (1.55 to 9.31) & 1.77 & 1.39 to 2.25 & $<0.001 \dagger$ & 1.23 & 0.94 to 1.59 & 0.42 \\
\hline
\end{tabular}

quartile of ever smokers the independent relative odds ratio (OR) for incident smoking in year 7 was 1.45 (95\% confidence interval (CI) 1.11 to 1.89 ). This effect was stronger in those children not exposed to parental smoking (OR for highest $v$ lowest quartile of year 7 tutor group smoking in children with parents who do not smoke $1.79,95 \%$ CI 1.19 to 2.69 , interaction $\mathrm{p}$ value 0.06 ). There was no suggestion of interaction between tutor group smoking and sibling smoking. The population attributable risk fraction calculations estimated that parental, sibling, and year 7 tutor group ever smoking accounted respectively for $20 \%, 18 \%$, and $20 \%$ of incident smoking during year 7 .

\section{DISCUSSION}

The years that a child spends in secondary education represent a crucial period of risk of incident smoking. Of children joining secondary education in Britain at age 11 , only $3 \%$ are regular or occasional smokers; by age 15 the figure is $31 \%{ }^{4}$ Addiction to nicotine is established in about half of young smokers within one year from starting to experiment with cigarettes, ${ }^{14}$ and in most cases results in continued smoking for decades. ${ }^{315}$ If smoking is to be prevented, it is essential to understand the major determinants of incident smoking during the early years in secondary school. Peer group and family influences are likely to be important in this respect. ${ }^{16-19}$

When children move into secondary education in Nottinghamshire they join tutor groups that are selected to promote mixing of children from different geographical areas and of different academic abilities. During the first year of secondary school, children spend the majority of the school day in this tutor group, and thus develop new friendships and experience new peer group pressures from within it. Although in special cases pairs of best friends from a primary school may sometimes be kept together, this is not standard practice and disruptive friendship groups are usually deliberately separated. Therefore, while the presence of some pairs of friends in tutor groups may confound the effect of tutor group ever smoking on incident smoking to some extent, the majority of children will also experience substantial new peer group influence, particularly during their first secondary school year. Our finding that the prevalence of ever smoking in the new tutor group is a significant independent determinant of incident smoking therefore suggests a direct influence of peer group ever smoking on individual smoking risk rather than an effect of peer group selection. In our study this effect, along with the effect of smoking at home, accounted for much of the effect of social deprivation on smoking ${ }^{20}$ suggesting that the high prevalence of smoking in disadvantaged populations is partly self perpetuating through high levels of exposure to other smokers. The general implication of our findings is that incident smoking in adolescence may be viewed as a communicable behaviour, and that prevention of exposure to smokers by effective policies on smoking at school and elsewhere may be a powerful method of controlling and preventing the uptake of smoking in the general population.

Our data were obtained using questions adapted from those used previously in national studies of smoking in UK adolescents, ${ }^{48}$ collected as part of a project designed to develop cessation services for teenage smokers in older school year groups. The socioeconomic status of our sample as measured by the Townsend Material Deprivation Index was slightly higher than the national average, which would lead us to expect a slightly lower than average prevalence of smoking; however, the overall educational achievement of children in the schools we studied was below average and children with low expectations of educational achievement are more likely to smoke. ${ }^{4}$ Our findings of a higher prevalence of smoking in girls, and with increasing age and social deprivation, are broadly similar to those reported nationally, ${ }^{4}$ and suggest that our findings are likely to reflect those of the national population of teenage smokers attending school in the UK. However, this inference needs to be cautioned by the fact that our 
measure of the school year when smokers reported that they had tried their first cigarette was retrospective and as such may be subject to recall bias. Ideally this study now needs to be repeated in a longitudinal design, with additional measures of smoking in friendship groups.

The aetiology and natural history of smoking in adolescence is complex, ${ }^{21}$ and factors other than school or home smoking exposure are clearly important in determining the onset and continuation of smoking. ${ }^{17}$ Previous researchers have suggested that the mechanism by which peers effect adolescent smoking is not a direct result of pressure from peers who smoke, but rather a combination of modelling and normative influences in which peers who smoke do not encourage smoking, but do not provide any discouragement from smoking. ${ }^{10}$ Others have found that those outside friendship groups are more likely to smoke than those within. ${ }^{22}$ Pupils who were ever smokers in year 7 include current and past smokers as well as some who may have only experimented with cigarettes. Considerable movement into and out of smoking has been observed during school years, ${ }^{23}$ so it seems likely that during year 7 there would have some shifting between the different categories of smoking for these ever smokers. We postulate that exposure to ever smokers may influence non-smokers through their being more likely to frequent smoking places, or by being more likely to be among smokers or by making trying smoking appear "normal" and by not providing any discouragement from trying smoking. Trying smoking is important since many young people who try cigarettes subsequently go on to become regular smokers, ${ }^{23}$ many of whom will continue smoking for several decades.

Our finding in relation to exposure of other ever smokers at school has important legal and health implications, since parents and pupils are entitled to expect that schools will not permit exposure of children to significant health hazards. Although some exposure may well have taken place out of school (suggesting the need for policies in other places young people frequent), it seems likely that at this age, school exposure may be of greater importance. To date, exposure to environmental tobacco smoke has been recognised as an occupational or school health issue in relation to the direct adverse effects of smoking on individual health, but the effect on the personal risk of becoming a regular smoker has not. Our findings suggest that non-smoking policies in school need to be encouraged and/or enforced much more to prevent this school peer group exposure. A similar conclusion probably applies to teacher smoking, though we have not explored this influence in the present study. Our suggestion that preventing exposure to smoking in school could have an important impact on adolescent smoking incidence is supported by evidence that restriction of exposure to smokers in other locations can reduce smoking prevalence. ${ }^{24-26}$ Although schools based smoking prevention programmes that focus on developing children's individual social skills in resisting peer pressure have to date been of limited value, ${ }^{27}$ a recent study has shown that schools with strong, strictly enforced smoking policies tend to have a lower prevalence of smoking than schools with weak or poorly enforced smoking policies. ${ }^{28}$ Our findings suggest that a further benefit of effective non-smoking policies at school may be to reduce smoking not only in established smokers, but also to delay or possibly prevent incident smoking in young people.

\section{ACKNOWLEDGEMENTS}

The authors thank Paul Mein for his cooperation and support in organising the surveys in schools, the head teachers, staff, and pupils who participated, and the Wellcome Trust for funding the study.

\section{Authors' affiliations}

A Molyneux, S Lewis, M Antoniak, R Hubbard, J Britton, University of Nottingham, Division of Respiratory Medicine, City Hospital,

\section{What this paper adds}

Most adult smokers start smoking during their early years in secondary education. The major influences on smoking behaviour during this period are not well understood. In particular, it is not clear whether peer group smoking, which is a recognised correlate of smoking in adolescence, arises from self selection of smoking peers or has a causal influence on smoking behaviour.

This study shows that in addition to the established effects of female sex and parental and sibling smoking on individual smoking risk, incident smoking is more likely in children who join a new secondary school tutor group with a high prevalence of ever smoking. This effect is not caused by self selection of smoking peers, since tutor group membership is determined independently from smoking status, and is therefore likely to be causal. The effect of the prevalence of ever smoking in tutor groups accounts for one quarter of incident smoking in the first year of secondary school. Adolescent smoking is thus a communicable disorder, and may be preventable by measures that reduce exposure to other smokers.

Nottingham, UK

A McNeill, Department of Psychology, St George's Hospital Medical School, London, UK

C Godfrey, University of York, Centre for Health Economics, York, UK R Madeley, University of Nottingham, Division of Public Health

Medicine, University Hospital, Nottingham, UK

\section{REFERENCES}

1 Department of Health. Smoking kills. A White Paper on tobacco. London: The Stationery Office, 1998.

2 Peto R. Smoking and death: the past 40 years and the next 40. BM 1994;309:937-9.

3 Royal College of Physicians. Nicotine addiction in Britain. A report of the tobacco advisory group of the Royal College of Physicians. London: Royal College of Physicians of London, 2000.

4 Higgins V. Young teenagers and smoking in 1998. A report of the key findings from the teenage smoking attitudes survey carried out in England in 1998. London: Office for National Statistics, 2000.

5 Engels RC, Knibbe RA, Drop M, et al. Homogeneity of cigarette smoking within peer groups: influence or selection? Health Educ Behav 1997;24:801-11.

6 Ennett ST, Bauman KE, Koch GG. Variability in cigarette smoking within and between adolescent friendship cliques. Addict Behav 1994;19:295-305.

7 Urberg KA, Cheng CH, Shyu SJ. Grade changes in peer influence on adolescent cigarette smoking: a comparison of two measures. Addict Behav 1991;16:21-8.

8 Anon. Teenage smoking attitudes N1449. London: Office for National Statistics, 1998

9 Botvin GJ, Botvin EM, Baker E, et al. The false consensus effect: predicting adolescents' tobacco use from normative expectations. Psychol Rep 1992;70:171-8.

10 Urberg KA, Shyu SJ, Liang J. Peer influence in adolescent cigarette smoking. Addict Behav 1990;15:247-55.

11 Bewley BR, Day I, Ide L. Smoking by children in Great Britain. London: SSRC/MRC, 1973.

12 Townsend $\mathbf{P}$, Phillimore B, Beattie A. Health and deprivation: inequality and the north. London: Croom Helm, 1988.

13 Breslow NE, Day NE. Statistical methods in cancer research. Volume 1 The analysis of case-control studies. Lyon: International Agency for Research on Cancer, 1980.

14 Di Franza JR, Rigotti NA, McNeill AD, et al. Initial symptoms of nicotine dependence in adolescents. Tobacco Control 2000;9:313-9.

15 Jarvis MJ. Patterns and predictors of smoking cessation in the general population. In: Bolliger CT, Fagerstrom KO, eds. The tobacco epidemic. Basel: Karger, 1997:151-64.

16 Royal College of Physicians. Personal and social factors influencing smoking. Smoking and the young. London: Royal College of Physicians of London, 1992.

17 Conrad KM, Flay BR, Hill D. Why children start smoking cigarettes: predictors of onset. Br J Addiction 1992;87:1711-24.

18 Flay BR, Hu FB, Siddiqui O, et al. Differential influence of parental smoking and friends' smoking on adolescent initiation and escalation of smoking. J Health Soc Behav 1994;35:248-65.

19 Stanton WR, Silva PA. Children's exposure to smoking. Int J Epidemiol 1991;20:933-7.

20 Jarvis MJ, Wardle J. Social patterning of individual health behaviours: the case of cigarette smoking. In Marmot M, Wilkinson R, eds. Social determinants of health, Oxford: Oxford University Press, 1999. 
21 Tyas SL, Pederson LL. Psychosocial factors related to adolescent smoking: a critical review of the literature. Tobacco Control 1998;7:409-20.

22 Ennett ST, Bauman KE. Peer group structure and adolescent cigarette smoking: a social network analysis. J Health Soc Behav 1993:34:226-36.

$23 \mathrm{McNeill}$ AD. The development of dependence on smoking in children. $\mathrm{Br}$ J Addiction 1991;86:589-92.

24 Wakefield MA, Chaloupka FJ, Kaufman NJ, et al. Effect of restrictions on smoking at home, at school, and in public places on teenage smoking: cross sectional study. BM 2000;321:333-7.
25 Biener L, Harris JE, Hamilton W. Impact of the Massachusetts tobacco control programme: population based trend analysis. BM 2000:321:351-4.

26 Farkas AJ, Gilpin EA, White MM, et al. Association between household and workplace smoking restrictions and adolescent smoking. JAMA 2000;284:717-22

27 NHS Centre for Reviews and Dissemination. Preventing the uptake of smoking in young people. Effective Health Care 1999;5:1-12.

28 Moore L, Roberts C, Tudor-Smith C. School smoking policies and smoking prevalence among adolescents: multilevel analysis of cross-sectional data from Wales. Tobacco Control 2001;10:1 17-23.

\section{The lighter side}

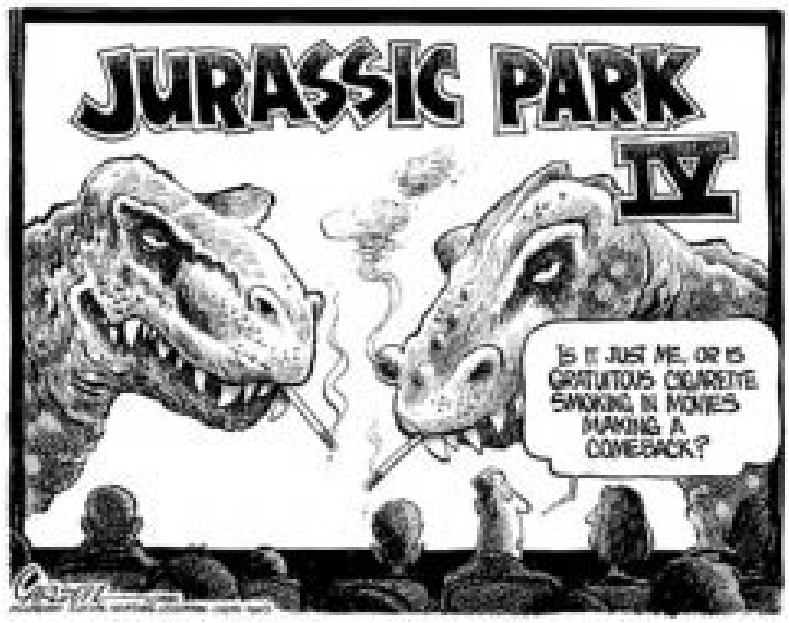

(C) Stuart Carlson 2002, Milwaukee Journal Sentinel.

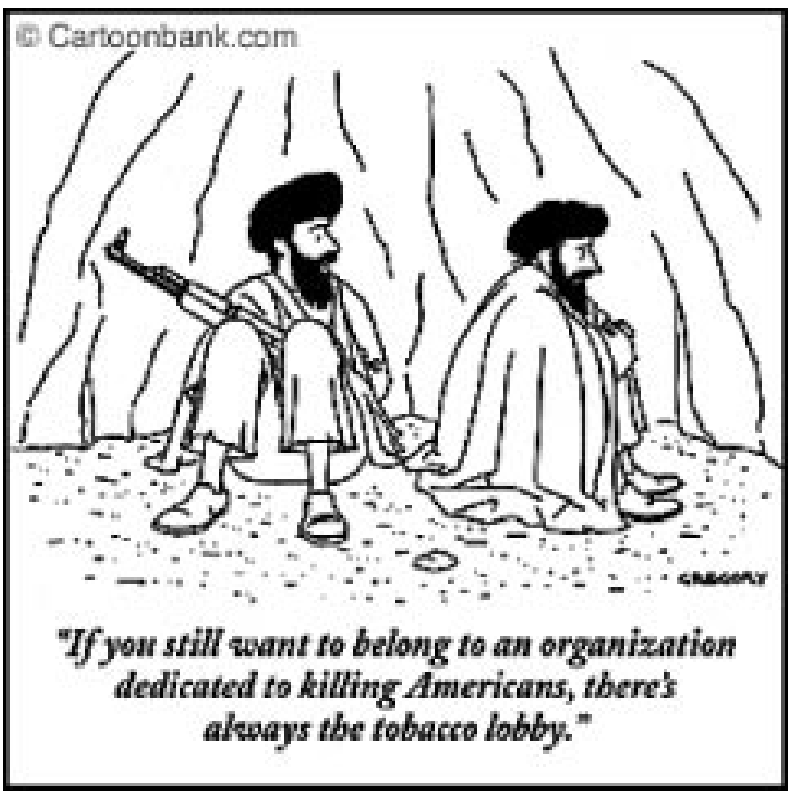

(C) The New Yorker Collection 2002 Alex Gregory from Cartoonbank.com. All Rights Reserved. 